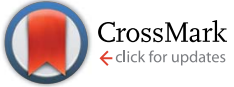

Cite this: J. Anal. At. Spectrom., 2015, 30, 1590

\title{
Multianalytical characterization of Late Roman glasses including nanosecond and femtosecond laser induced breakdown spectroscopy
}

\begin{abstract}
M. Oujja, ${ }^{\text {aa M. Sanz }}{ }^{a}$ F. Agua, ${ }^{b}$ J. F. Conde, ${ }^{b}$ M. García-Heras, ${ }^{b}$ A. Dávila, ${ }^{c}$ P. Oñate, ${ }^{d}$ J. Sanguino, ${ }^{d}$ J. R. Vázquez de Aldana, ${ }^{e}$ P. Moreno, ${ }^{e}$ M. A. Villegas ${ }^{b}$ and M. Castillejo ${ }^{a}$

In the present study, a historical set of Late Roman glasses from a recently unearthed graveyard located in the small city of Cubas de la Sagra, within the Madrid region (Spain) was compositionally analysed using different techniques such as ultraviolet-visible (UV-Vis) and laser induced fluorescence (LIF) spectroscopy, X-ray fluorescence (XRF) and laser induced breakdown spectroscopy (LIBS). LIBS results, recorded upon nanosecond (ns) and femtosecond ( $f s$ ) laser irradiation, served for identification of major glass components (to classify them into main historical glass groups) and of minor components (e.g. chromophores, decolouring agents and degradation products). Quantitative information regarding these components was obtained on the basis of calibration curves obtained using glass certified standards and local standards. We have demonstrated that LIBS serves for the non-invasive/micro-destructive, quantitative chemical characterization of most of the analysed historical glasses. Furthermore, this work establishes a comparison between LIBS analysis of glasses in the ns and fs regimes on one hand, and on the other hand with the results obtained using XRF. The procedures and protocols here proposed can be applied for in situ study of historical glass collections, regardless of their size, provenance and chronology.
\end{abstract}

Received 13th April 2015

Accepted 28th April 2015

DOI: 10.1039/c5ja00150a

www.rsc.org/jaas available about the influence of laser pulse duration on LIBS analysis. ${ }^{14-16}$ With the introduction of ultra-short laser pulses in the picosecond (ps) and femtosecond (fs) ranges, great interest in investigating the advantages offered by these laser sources for spectrometric applications, such as LIBS, has been developed both in single or double pulse approaches. ${ }^{14,17-20}$ The physical mechanisms involved in ultrashort fs laser ablation differ from those taking place with nanosecond (ns) pulses. Because of their very short duration, fs pulses do not interact with the resulting plasma; thus the absorbed laser energy is fully deposited into the material at the solid density, with little thermal diffusion while the pulse is on. The shortening of laser pulse duration decreases the size of the heat-affected-zone and leads to more controllable material modification and removal. The reduced thermal effects also help to achieve stoichiometric ablation which improves the analytical performance of the technique. On the other hand, for longer ns pulses, increased heat conduction takes place inside the target during ablation and significant laser energy is absorbed by the expanding plasma, which increases the efficiency of conversion from laser energy to plasma energy and thus to radiation.

Common laboratory-based techniques used for characterizing historical glasses, such as X-ray fluorescence spectrometry (XRF) and scanning electron microscopy/energy-dispersive X-ray spectroscopy (SEM/EDX), are usually destructive, as sampling is necessary and the removed material has to be ground for analysis. Although portable XRF systems are 
becoming more available, the above mentioned techniques cannot be applied for non-destructible samples of considerable or relatively large size, from museum collections, or for glass items that must be reintegrated into a work of art, as for instance, stained glass windows. Although LIBS has been used in several archaeometrical studies of different cultural heritage materials, ${ }^{21-26}$ those devoted to historical glasses are scarce. These studies have focused on finding the optimal LIBS parameters for the analysis of model soda lime silicate ${ }^{27}$ and historical lead silicate glasses ${ }^{28}$ on the characterization of chromophores and opacifiers of ancient glasses, and on degradation pathologies. ${ }^{29-31}$ LIBS has proved to be effective for studying glasses from a wide variety of perspectives. ${ }^{27-33}$ However, the potential of LIBS as a micro-destructive technique for quantitative bulk chemical composition analysis of ancient glasses remains almost unexplored.

For quantitative compositional material analysis by LIBS, two approaches are available. The widely used calibration-based method relies on certified reference materials which are measured by LIBS. ${ }^{28,33}$ Calibration curves are derived for specific elements that are used to determine their content in the substrate under study. To achieve a good level of detection it is necessary to use matrix-matched reference materials and to apply similar experimental conditions for measuring the samples and the references. The second technique is based on a calibration-free procedure, where the laser-induced plasma and the optical plasma emission are modeled and directly yield the composition of the sample material from the LIBS spectra. ${ }^{32,34}$

In the present work we present a comparative quantitative analysis by LIBS of an outstanding set of Late Roman glasses using both ns and fs laser pulses. Calibration curves were obtained based on LIBS measurements on standard and certified glasses. The obtained results were compared and integrated with those provided by XRF, ultraviolet-visible spectroscopy (UV-Vis) and Laser Induced Fluorescence (LIF).

\section{Experimental}

\section{Description of samples}

The study focuses on a set of glass fragments of the Late Roman period from a recently unearthed graveyard located in the small city of Cubas de la Sagra (Madrid region, Spain). Fig. 1 shows the selected glass fragments. The graveyard, which is associated with an important craftsmen settlement site, is constituted by two zones only separated by $200 \mathrm{~m}$. The first area (Area 1), of approximately $80 \mathrm{~m}^{2}$, has been completely excavated and has provided 10 graves, whereas the second area (Area 2), of nearly $10500 \mathrm{~m}^{2}$ and still partially excavated, has provided 142 graves up to now, even though at least 119 others have been located. The graves identified in both areas have been dated between the late $4^{\text {th }}$ and mid $5^{\text {th }}$ century $\mathrm{AD}$ and mainly correspond to individual burials oriented NW-SE. Only 24 graves have provided goods consisting of ceramic vessels and glass recipients while glass fragments have been found in only 18 of these 24 graves. Such fragments belonged presumably to bowls and beakers, mainly in the 96 Isings form. ${ }^{35}$ Colourless and olive green are the predominant colours of the excavated glass items.
Nine glass samples (two from Area 1 and seven from Area 2) have been selected for the investigation herein. Table 1 lists the main characteristics of these samples.

\section{Analytical techniques}

The glass samples were compositionally analysed using a set of analytical techniques including XRF, UV-Vis, LIF and LIBS.

Chemical analyses by XRF were carried out with a PANalytical Axios wavelength dispersed X-ray spectrometer equipped with a rhodium tube of $4 \mathrm{~kW}$ and $60 \mathrm{kV}$. Analytical determinations were undertaken through the standard-less analytical software IQ+ (PANalytical) from synthetic oxides and natural minerals. XRF analyses were carried out on powder samples prepared by grinding body glass fragments, with their most external surfaces removed, by polishing in an agate mortar.

UV-Vis spectra of the samples were acquired with an Ocean Optics HR 4000 CG system. Spectra were recorded in the 250-1100 $\mathrm{nm}$ range on glass sections of approximately $1 \mathrm{~mm}$ in thickness, obtained by polishing both sides for optical quality.

LIF measurements were carried out using laser excitation at $266 \mathrm{~nm}\left(4^{\text {th }}\right.$ harmonic of a Q-switched Nd:YAG laser, $6 \mathrm{~ns}$ pulses, $10 \mathrm{~Hz}$ repetition rate) and a $0.30 \mathrm{~m}$ spectrograph with a 300 grooves per mm grating (TMc300 Bentham) coupled to an intensified charged coupled detector (2151 Andor Technologies). The temporal gate was operated at zero time delay with respect to the arrival of the pulse to the surface of the sample and with a width of $3 \mu \mathrm{s}$. The sample was illuminated by the laser at an incidence angle of $45^{\circ}$ with pulses of around $0.1 \mathrm{~mJ}$. For the results presented here, a $420 \mathrm{~nm}$ cut-off filter was set in front of the spectrograph to avoid the second order emissions of lower wavelengths. Each spectrum resulted from the accumulation of 20 measurements in five different points of each sample zone.

LIBS analysis was performed using two different systems based on ns and fs lasers. The first system consists of both the laser source and the spectrograph-ICCD detection systems described above for acquisition of LIF spectra. The laser beam was also directed to the surface of the glass samples by the use of mirrors at an incidence angle of $45^{\circ}$. We used irradiation fluences of $6.6 \mathrm{~J} \mathrm{~cm}^{-2}$ by focusing with a $10 \mathrm{~cm}$ focal length lens, to a spot diameter size of $240 \mu \mathrm{m}$, pulses of $3 \mathrm{~mJ}$. This fluence ensures a good signal/noise ratio and good reproducibility of LIB spectra. The shot to shot laser energy fluctuation was less than $10 \%$ and LIB spectra were recorded at $70 \mathrm{~nm}$ intervals with a 300 grooves per $\mathrm{mm}$ grating in the $250-600 \mathrm{~nm}$ wavelength range at a $0.025 \mathrm{~nm}$ resolution. A cut-off filter at $320 \mathrm{~nm}$ was placed in front of the entrance window of the spectrograph to reduce the scattered laser light from the surface of the sample and to avoid the second-order diffraction. The gate delay and width were adjusted to both minimize the early continuous bremsstrahlung emission and maximize the light emitted by ionized species present at the initial stages of the ablation plasma and which usually contains useful analytical information. We noticed that contribution of bremsstrahlung was negligible even at zero time delay (see section on LIBS below) 


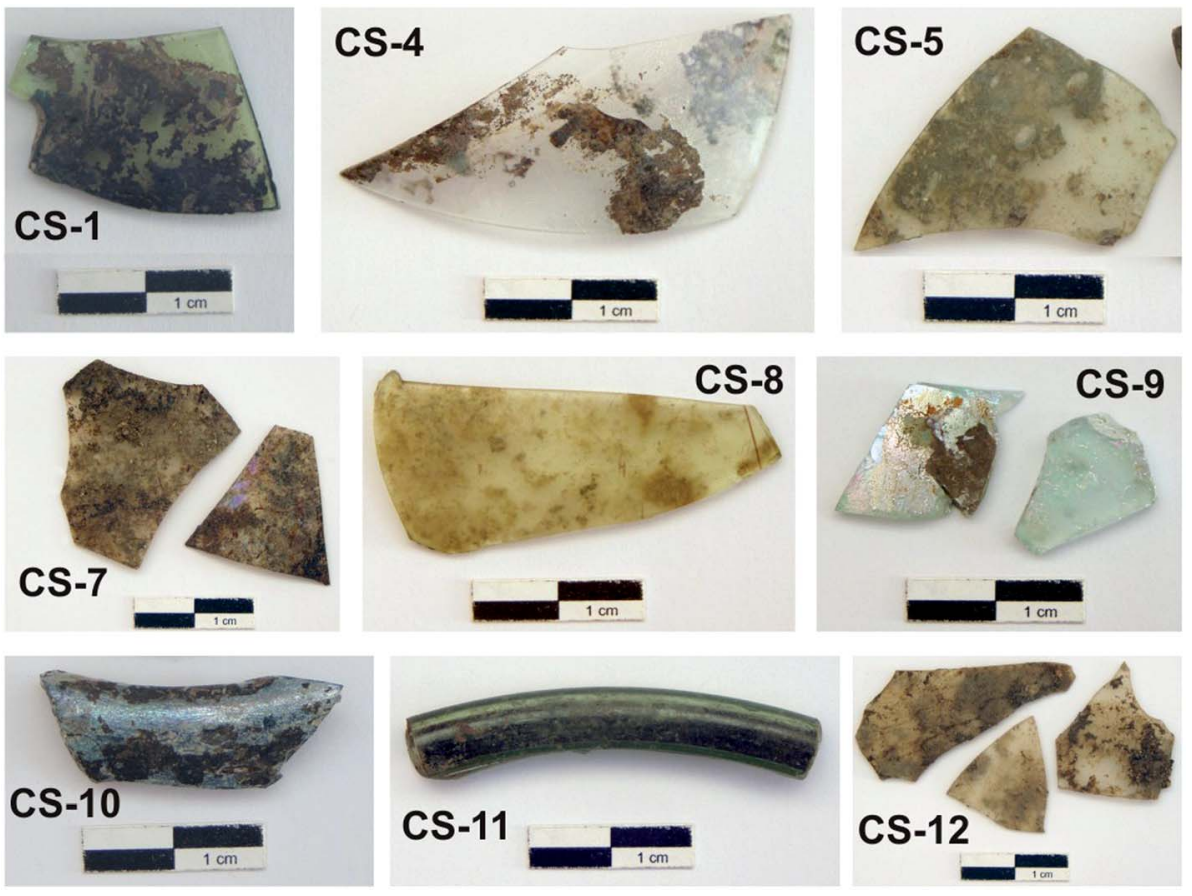

Fig. 1 Images of the selected Late Roman glass samples.

and selected values of 0 and $1 \mu$ s for gate delay and width, respectively. Spectra resulted from summing up the emissions from ten successive laser pulses, which helped to improve even more the signal/noise ratio.

The second LIBS system is based on a commercial Ti:Sapphire oscillator (Tsunami, Spectra Physics) and a regenerative amplifier system (Spitfire, Spectra Physics) based on the chirped pulse amplification technique. This laser produces linearly polarized $120 \mathrm{fs}$ pulses at $800 \mathrm{~nm}$ with a repetition rate of $1 \mathrm{kHz}$. The pulse energy can reach a maximum of $1 \mathrm{~mJ}$ and it is finely controlled by a half-wave plate and a linear polarizer. For ablation, the laser beam spot was concentrated on the surface of the sample to a diameter of $32 \mu \mathrm{m}$ with a $10 \mathrm{~cm}$ focal length lens. Reproducible spectra with a good signal/noise ratio were obtained using pulse energies of $200 \mu \mathrm{J}$ yielding fluences of $24 \mathrm{~J}$ $\mathrm{cm}^{-2}$. The LIB spectra were recorded using a spectrograph (Shamrock SRS 303i) coupled to a time gated ICCD camera (iSTAR DH734i-18F-03 Andor Technologies) with a $0.025 \mathrm{~nm}$ resolution. In this case the spectra were obtained by accumulation of the signal produced by ablation with fifty successive laser pulses at the maximum repetition rate of the laser of 1 $\mathrm{kHz}$. The plasma generated during the interaction of fs laser pulses with the sample leaves the ablation region at very high speeds (in the range of thousands of $\mathrm{m} \mathrm{s}^{-1}$ ). The interaction of a given incoming pulse with ablated species produced by the previous one (arriving at the target $1 \mathrm{~ms}$ earlier) is negligible and the LIBS signal recorded by accumulation of successive pulses is the simple addition of individual single pulse emissions. As in the ns-based LIBS system previously described, we optimized the spectral acquisition for the best reproducibility and signal/noise ratio using a gate delay and width of 0 and $1 \mu \mathrm{s}$, respectively.

The comparison between ns and fs LIBS results was based on the best performance for each approach, by considering in each case fluence and temporal gate parameters that allow the best reproducibility and signal/noise ratio. No attempt was made to

Table 1 Characteristics of studied Late Roman glasses

\begin{tabular}{|c|c|c|c|c|c|}
\hline Sample & Part number & Graveyard area & Thickness (mm) & Colour & Remarks \\
\hline CS-1 & 21500-2 V1 & 1 & 1.1 & Olive green & Dark deposits \\
\hline CS-4 & $26100-3 \mathrm{~V} 3$ & 1 & 0.7 & Colourless & Earthy deposits \\
\hline CS-5 & $50500-2 \mathrm{~V} 1$ & 2 & 0.7 & Colourless & Earthy deposits and bubbles \\
\hline $\mathrm{CS}-7$ & $50700-3 \mathrm{~V} 1$ & 2 & 0.6 & Colourless & Earthy deposits and micro-cracks \\
\hline CS-8 & $56400-1 \mathrm{~V} 1$ & 2 & 1.4 & Yellowish colourless & Earthy deposits \\
\hline CS-9 & $74300-2 \mathrm{~V} 1$ & 2 & 2.2 & Bluish colourless & Iridescence layer and earthy deposits \\
\hline CS-10 & $98400-1 \mathrm{~V} 1$ & 2 & 7.0 & Blue & Dark deposits \\
\hline CS-11 & 114100-1 V1 & 2 & 6.2 & Olive green & Few earthy deposits \\
\hline CS-12 & $114300-2 \mathrm{~V} 1$ & 2 & 0.7 & Colourless & Earthy deposits \\
\hline
\end{tabular}


use comparable ns and fs pulse energies because of the difficulty of inducing reproducible ablation sparks at very low energies by using ns excitation.

\section{Results and discussion}

\section{X-ray fluorescence}

The historical Late Roman glasses were quantitatively analyzed by XRF. Table 2 shows the chemical composition determined by this technique. In all the analyses $\mathrm{SiO}_{2}$ and $\mathrm{Na}_{2} \mathrm{O}$ are the major components, with contents in wt\% ranging between 63-68 and 16-19, respectively. Historically, a high $\mathrm{SiO}_{2}$ and $\mathrm{Na}_{2} \mathrm{O}$ content ensured the improvement of the glass chemical resistance. Small amounts of other oxides, e.g. $\mathrm{Fe}_{2} \mathrm{O}_{3}, \mathrm{MnO}$ and $\mathrm{CuO}$ are also found. These oxides were added to the raw materials with the intention of colouring the glass. Other minor components found $\left(\mathrm{Al}_{2} \mathrm{O}_{3}, \mathrm{MgO}, \mathrm{BaO}, \mathrm{PbO}\right.$, etc. $)$ can be attributed to impurities of the raw materials employed in the manufacturing process.

Besides the historical glasses, standard and homemade model glasses were analyzed and used as calibration patterns for LIBS quantitative determinations. The obtained results are displayed in Table 3. The standard glasses are soda-lime-silica glass (Gl-1, standard glass no. 7), lead oxide-potassium oxidesilica glass (Gl-2, standard glass no. 8) and amber soda-limesilica glass (Gl-3, SGT 10) provided by the Society of Glass Technology, UK. The homemade model glasses (Gl-4 to Gl-7) were prepared on the occasion of a previous study, ${ }^{28}$ and were chosen due to their similar chemical composition to the historical ones subject of the present investigation.

\section{UV-Vis spectroscopy}

The colour characterization of glasses, i.e. the detection of their chromophores, was performed by UV-Vis spectroscopy. Among the set of samples, representative colourless, olive green, yellowish colourless, bluish colourless and blue colorations were selected. All the samples studied show one of these colours (Table 1 and Fig. 1). Small pieces of the samples to be analyzed were cut and polished to optical quality by both sides and, when necessary, they were transformed into plano-parallel slabs, with thickness equal or less than the original thickness of the glass samples as received.

Fig. 2 shows the UV-Vis spectra of some of the samples studied (CS-1, CS-4, CS-8, CS-9 and CS-10). The spectrum of the olive green glass CS-1 (Fig. 2a) presents absorption bands due to the pair $\mathrm{Fe}^{2+} / \mathrm{Fe}^{3+}$, at 420 and $440 \mathrm{~nm}$, assigned to $\mathrm{Fe}^{3+}$ (yellow colour) and at around 1050-1100 nm assigned to $\mathrm{Fe}^{2+}$ (blue colour). The simultaneous presence of both oxidation states of iron ions causes the chromatic addition of their respective absorption bands, which explains its green colour. Therefore the olive hue of the CS-1 green glass (Fig. 1) comes from the relative intensity of the bands of both oxidation states of iron ions. This result is confirmed by the chemical composition derived from the XRF analysis. The total iron oxide concentration of this sample is $2.31 \mathrm{wt} \%$, as reported in Table 2. The 2.48 $\mathrm{wt} \%$ content of manganese oxide for this sample is too low to

Table 2 Chemical composition in (wt\%) from XRF measurements carried out on historical glasses

\begin{tabular}{|c|c|c|c|c|c|c|c|c|c|c|c|c|c|c|c|c|c|}
\hline Sample & $\mathrm{Na}_{2} \mathrm{O}$ & $\mathrm{MgO}$ & $\mathrm{Al}_{2} \mathrm{O}_{3}$ & $\mathrm{SiO}_{2}$ & $\mathrm{P}_{2} \mathrm{O}_{5}$ & $\mathrm{SO}_{3}$ & $\mathrm{Cl}^{-}$ & $\mathrm{K}_{2} \mathrm{O}$ & $\mathrm{CaO}$ & $\mathrm{TiO}_{2}$ & $\mathrm{MnO}$ & $\mathrm{Fe}_{2} \mathrm{O}_{3}$ & $\mathrm{CuO}$ & $\mathrm{SrO}$ & $\mathrm{Sb}_{2} \mathrm{O}_{3}$ & $\mathrm{BaO}$ & $\mathrm{PbO}$ \\
\hline CS-1 & 17.05 & 0.94 & 2.60 & 65.49 & 0.05 & 0.26 & 1.07 & 0.47 & 6.52 & 0.68 & 2.48 & 2.31 & 0.01 & 0.04 & $-^{a}$ & 0.03 & $-^{a}$ \\
\hline CS-4 & 16.05 & 0.68 & 2.49 & 67.01 & 0.13 & 0.36 & 0.94 & 0.75 & 9.89 & 0.08 & 1.07 & 0.50 & 0.01 & 0.04 & $-^{a}$ & $-^{a}$ & $-^{a}$ \\
\hline CS-5 & 18.48 & 0.78 & 2.10 & 66.27 & 0.06 & 0.30 & 1.22 & 0.47 & 6.26 & 0.39 & 2.12 & 1.42 & $\leftarrow^{a}$ & 0.05 & $-^{a}$ & 0.08 & $-^{a}$ \\
\hline $\mathrm{CS}-7$ & 18.96 & 1.08 & 1.92 & 63.71 & 0.07 & 0.33 & 1.24 & 0.36 & 8.60 & 0.21 & 2.01 & 1.42 & ${ }^{a}$ & 0.07 & $-^{a}$ & 0.02 & $-^{a}$ \\
\hline CS-8 & 18.92 & 1.09 & 2.22 & 65.57 & 0.06 & 0.21 & 1.45 & 0.46 & 5.49 & 0.39 & 2.53 & 1.51 & 0.01 & 0.05 & $-^{a}$ & 0.04 & $-^{a}$ \\
\hline CS-9 & 18.70 & 0.54 & 1.93 & 67.83 & 0.12 & 0.31 & 1.33 & 0.71 & 7.15 & 0.10 & 0.36 & 0.64 & 0.01 & 0.04 & 0.18 & $ـ^{a}$ & 0.05 \\
\hline CS-10 & 18.80 & 0.84 & 1.78 & 66.78 & 0.04 & 0.18 & 1.52 & 0.38 & 6.16 & 0.12 & 1.31 & 0.98 & 1.06 & 0.04 & $-^{a}$ & $-^{a}$ & 0.01 \\
\hline CS-11 & 17.71 & 0.91 & 2.22 & 67.85 & 0.05 & 0.24 & 1.28 & 0.40 & 5.00 & 0.44 & 2.27 & 1.52 & $-^{a}$ & 0.04 & $-^{a}$ & 0.07 & $-^{a}$ \\
\hline CS-12 & 17.37 & 0.78 & 1.84 & 66.92 & 0.04 & 0.32 & 1.59 & 0.46 & 7.94 & 0.13 & 1.57 & 0.92 & 0.01 & 0.07 & $-^{a}$ & 0.04 & $-^{a}$ \\
\hline
\end{tabular}

${ }^{a}$ Not detected.

Table 3 Chemical composition in (wt\%) derived from XRF measurements carried out on standard an homemade model glasses

\begin{tabular}{|c|c|c|c|c|c|c|c|c|c|c|c|c|c|c|c|c|c|c|}
\hline Sample & $\mathrm{Na}_{2} \mathrm{O}$ & $\mathrm{MgO}$ & $\mathrm{Al}_{2} \mathrm{O}_{3}$ & $\mathrm{SiO}_{2}$ & $\mathrm{P}_{2} \mathrm{O}_{5}$ & $\mathrm{SO}_{3}$ & $\mathrm{~K}_{2} \mathrm{O}$ & $\mathrm{CaO}$ & $\mathrm{TiO}_{2}$ & $\mathrm{MnO}$ & $\mathrm{Fe}_{2} \mathrm{O}_{3}$ & $\mathrm{Sb}_{2} \mathrm{O}_{3}$ & $\mathrm{BaO}$ & $\mathrm{PbO}$ & $\mathrm{Cr}_{2} \mathrm{O}_{3}$ & $\mathrm{~B}_{2} \mathrm{O}_{3}$ & $\mathrm{As}_{2} \mathrm{O}_{3}$ & $\mathrm{ZrO}_{2}$ \\
\hline Gl-1 & 13.90 & 0.14 & 1.50 & 72.64 & $-^{a}$ & 1.19 & 0.43 & 11.03 & 0.04 & $-^{a}$ & 0.04 & $-^{a}$ & $-^{a}$ & $-^{a}$ & $-^{a}$ & $-^{a}$ & $-^{a}$ & $-^{a}$ \\
\hline Gl-2 & 0.23 & $<0.02$ & 0.05 & 56.34 & $-^{a}$ & ${ }^{a}$ & 11.85 & $<0.02$ & 0.02 & $-^{a}$ & 0.01 & $-^{a}$ & $ـ^{a}$ & 30.59 & $-^{a}$ & 0.36 & 0.32 & $-^{a}$ \\
\hline Gl-3 & 12.20 & 1.81 & 1.62 & 72.68 & $-^{a}$ & 0.05 & 0.35 & 10.68 & 0.01 & 0.04 & 0.32 & $-^{a}$ & 0.02 & $-^{a}$ & 0.02 & ${ }^{a}$ & ${ }^{a}$ & 0.02 \\
\hline Gl-4 & 0.09 & 0.03 & 0.21 & 59.28 & $-^{a}$ & ${ }^{a}$ & 15.81 & 0.13 & $-^{a}$ & 0.09 & 0.15 & 0.03 & $-^{a}$ & 24.05 & $-^{a}$ & $-^{a}$ & 0.13 & $-^{a}$ \\
\hline Gl-5 & 13.80 & 4.47 & 0.61 & 70.83 & 0.04 & $-^{a}$ & 0.43 & 9.69 & $-^{a}$ & $-^{a}$ & 0.12 & $-^{a}$ & $-^{a}$ & $-^{a}$ & $-^{a}$ & $ـ^{a}$ & $-a$ & $-^{a}$ \\
\hline Gl-6 & 0.70 & 3.22 & 3.34 & 47.33 & 2.87 & $-^{a}$ & 18.81 & 22.65 & $-^{a}$ & 1.02 & 0.06 & $-^{a}$ & $-^{a}$ & $-^{a}$ & $-^{a}$ & $-^{a}$ & $-^{a}$ & $-^{a}$ \\
\hline Gl-7 & 10.26 & 0.04 & 1.07 & 58.88 & $-^{a}$ & $-^{a}$ & 5.15 & 11.41 & $-^{a}$ & 1.29 & 3.56 & $-^{a}$ & 0.41 & 7.61 & $-^{a}$ & $-^{a}$ & 0.31 & $-^{a}$ \\
\hline
\end{tabular}

${ }^{a}$ Not detected. 


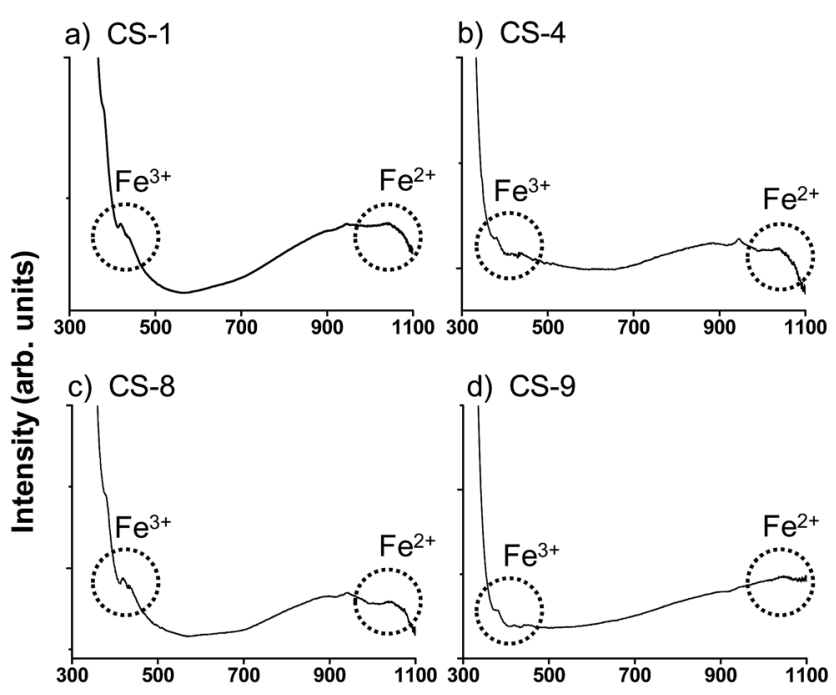

e) CS-10

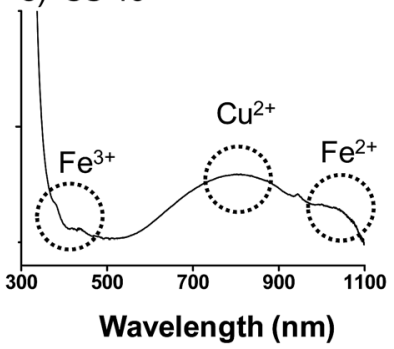

Fig. 2 UV-Vis spectra of glass samples: (a) olive green CS-1, (b) colourless CS-4, (c) yellowish colourless CS-8, (d) bluish colourless CS-9, and (e) blue CS-10. The labelled circles indicate the chromophores responsible of the observed bands.

produce an effective discoloration effect. This aspect will be detailed below.

The spectrum of the colourless glass CS- 4 is shown in Fig. $2 \mathrm{~b}$. In this case the absorption bands of the two oxidation states of the pair $\mathrm{Fe}^{2+} / \mathrm{Fe}^{3+}$ were also observed, although with lower intensity as compared to Fig. 2a. In fact, the total iron oxide percentage of this glass sample determined by XRF (Table 2) is as low as $0.50 \mathrm{wt} \%$. Such an amount of iron ions is not able to produce the residual greenish hue observed in sample CS-1. The absence of colour of CS-4 can be also explained by the presence of another chromophore, the $\mathrm{Mn}^{3+}$, whose absorption band at around $500 \mathrm{~nm}$ (pink colour) compensates the greenish coloration produced by iron ions. In fact, XRF results displayed in Table 2 confirm this statement, since the manganese oxide content detected by XRF in glass CS- 4 is higher than $1 \mathrm{wt} \%$. The use of manganese salts as a decolouring agent of glasses was well known by Roman glass-makers, who inherited this tradition from Assyrian glass artisans. ${ }^{36}$

The spectrum of Fig. 2c, which corresponds to the yellowish glass CS-8, is very similar to that shown in Fig. 2a. In this case, although both bands due to iron ions are present, the colour eventually looks yellowish instead of green, because the relative intensity of the absorption bands of $\mathrm{Fe}^{3+}$ (yellow) is higher than that of the corresponding band of $\mathrm{Fe}^{2+}$ (blue). The opposite case appears for the bluish sample CS-9 as shown in Fig. 2d, in which the intensity of bands of $\mathrm{Fe}^{2+}$ is higher than that of $\mathrm{Fe}^{3+}$. The presence of iron ions as chromophores in glasses CS- 8 and CS-9 was confirmed by XRF analyses (Table 2). In sample CS-8 the content of iron oxide detected was $1.51 \mathrm{wt} \%$, while it was 0.64 wt\% in sample CS-9. It is important to note that sample CS-8 also contains a noticeable amount of manganese oxide $(2.53$ $w t \%)$ that prevents, by means of the chromatic compensation mentioned above, a greenish appearance due to iron ions.

In Fig. 2e the spectrum of the blue glass CS-10 is shown. Besides the absorption bands assigned to $\mathrm{Fe}^{2+} / \mathrm{Fe}^{3+}$, a band due to $\mathrm{Cu}^{2+}$ appears at about $800 \mathrm{~nm}$. The blue colour produced by $\mathrm{Cu}^{2+}$ masks the light yellow colour due to $\mathrm{Fe}^{3+}$. As it can be seen in Table 2, copper oxide and iron oxide contents of glass CS-10 are about $1 \mathrm{wt} \%$. This sample also contains $1.31 \mathrm{wt} \%$ of manganese oxide, but in this case the manganese ions are unable to chromatically compensate the blue colour provided by $\mathrm{Cu}^{2+}$-ions.

As regards the production technology involved in producing the different colours observed in the set of glasses studied, the chromophores detected by UV-Vis spectroscopy indicate that yellowish and bluish hues could be the result of iron oxide impurities of the sand used for glass-making. The intense olive green colour comes from to one of these origins: (a) intentionally added iron oxide for colouring; (b) the use of sands containing high quantities of iron oxide impurities; (c) the use of

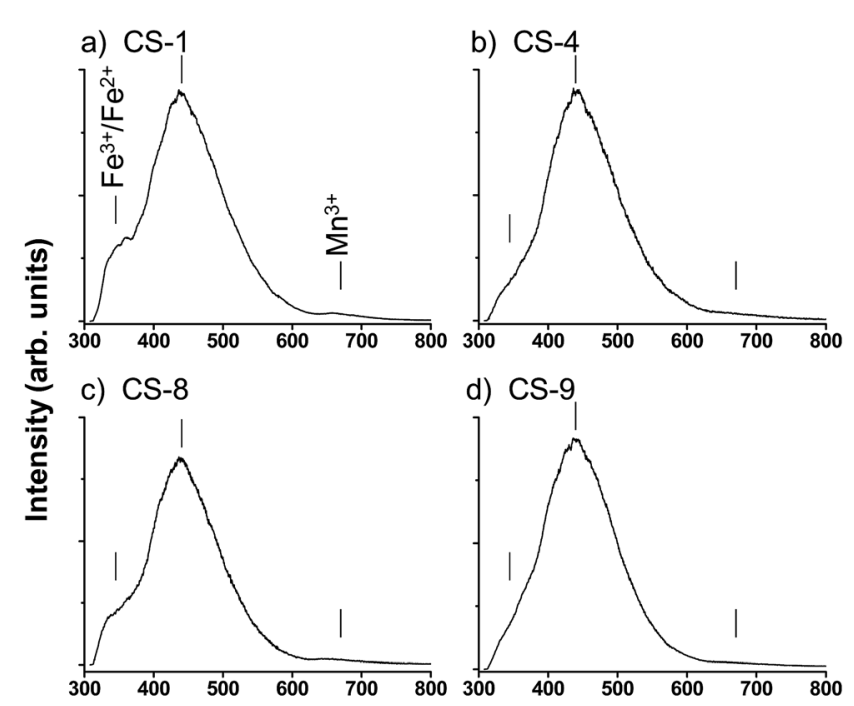

e) CS-10

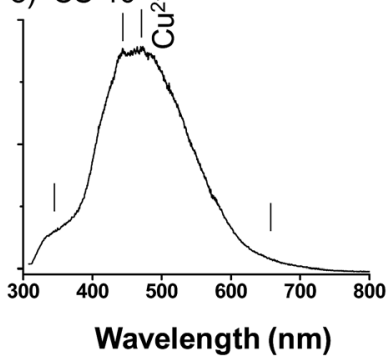

Fig. 3 LIF spectra of representative Late Roman glasses upon excitation at $266 \mathrm{~nm}$ : (a) olive green CS-1, (b) colourless CS-4, (c) yellowish colourless CS-8, (d) bluish colourless CS-9, and (e) blue CS-10. Spectral resolution is $5 \mathrm{~nm}$. 


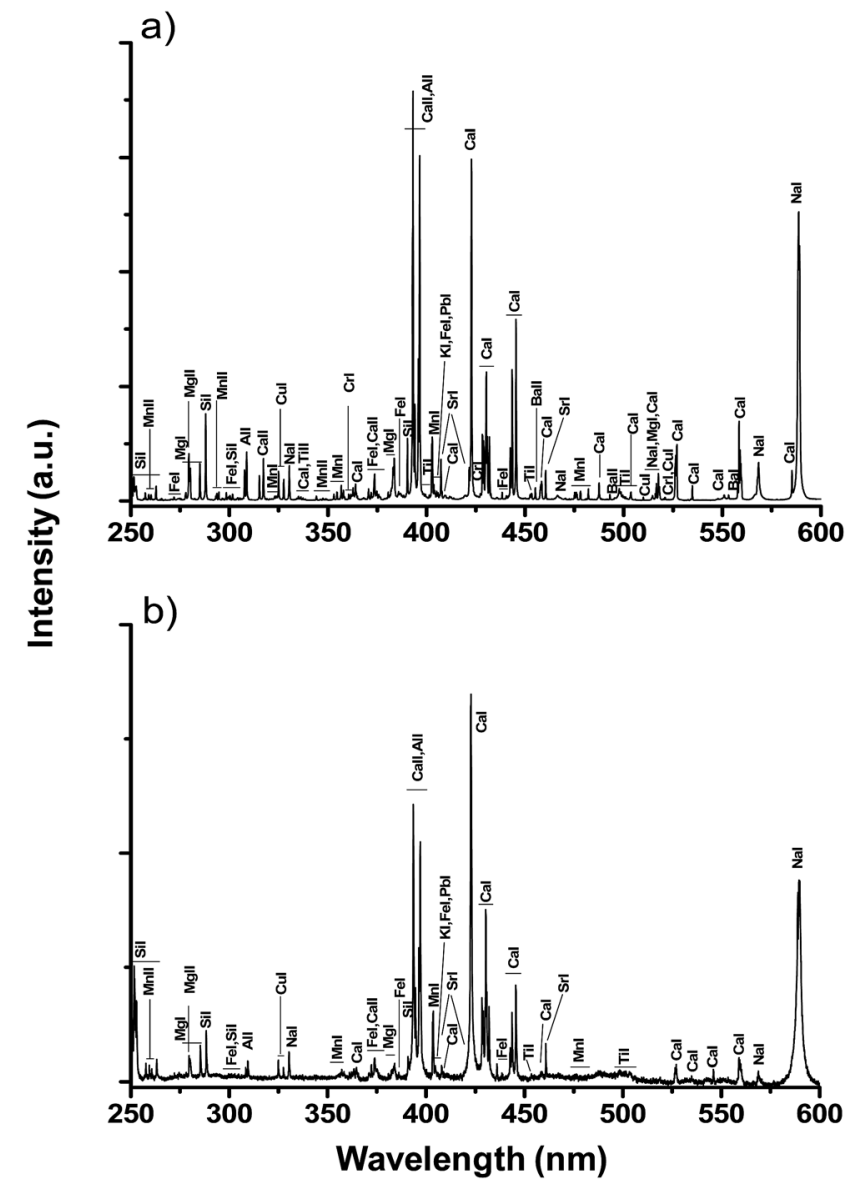

Fig. 4 Representative LIB spectra of historical glass sample CS-10 with: (a) nanosecond and (b) femtosecond laser excitation. The LIB spectra correspond to the accumulation of 15 laser pulses in the single pulse mode for $n s$ pulses and to the accumulation of 50 laser pulses in the scanning mode for fs pulses. The time delay and gate width were 0 and $1 \mu \mathrm{s}$, respectively. The vertical units are comparable in the two figures.

recycled glass, in which the iron impurities are concentrated and the mixture of different original colours is common. Among these three options, the third arises as the most probable, since, as it is well documented,,$^{37-39}$ in the $4^{\text {th }}$ and $5^{\text {th }}$ centuries AD the practice of recycling glass was widely extended throughout the Roman Empire.

\section{Laser induced fluorescence}

LIF spectra were collected on the bare surface of the samples upon laser excitation at $266 \mathrm{~nm}$ for each of the nine glasses selected for this study. Fig. 3 displays representative spectra.
Fig. 3a shows the spectrum of the olive green CS-1 glass, which consists of three broad bands centered at 350, 440 and $655 \mathrm{~nm}$. The emission observed at $350 \mathrm{~nm}$ was assigned to $\mathrm{Fe}^{2+} /$ $\mathrm{Fe}^{3+}$ chromophores. ${ }^{40,41}$ The bands at 440 and $655 \mathrm{~nm}$ correspond to the contribution of different glass fluorophores and to the $\mathrm{Mn}^{3+}$ chromophore, ${ }^{42}$ respectively. As shown before, the presence of these bands in the UV-Vis spectra (Fig. 2) supports such an assignment. The colorless CS-4 glass (Fig. 3b) displays the same LIF spectrum as that of CS-1 at reduced intensity. This decrease in intensity explains the absence of colour of CS-4 glass. The relative intensity of the bands observed in the LIF spectra of the remaining analyzed glasses, CS-5, CS-7, CS-8 (in Fig. 3c), CS-9 (in Fig. 3d), CS-11 and CS-12, is related to the content of iron and manganese oxides which defines their coloration. For CS-10 glass (Fig. 3e), in addition to the bands observed for the previous glasses, an additional over-imposed band, attributed to the $\mathrm{Cu}^{2+}$ chromophore is observed at $475 \mathrm{~nm} .{ }^{43}$ The presence of the $\mathrm{Cu}^{2+}$ is responsible for the blue colour of CS-10 glass. This result is in agreement with those obtained using UV-Vis spectroscopy reported above.

\section{Laser induced breakdown spectroscopy}

LIB spectra were recorded in the glass samples by ns and fs laser excitation. The spectra revealed their elemental composition according to the emission lines of main and minor components, including the chromophore compounds responsible of their colour. As an example, Fig. 4 shows the LIB spectra of sample CS-10 recorded using ns and fs pulses. The emission lines were assigned based on data from ref. 45. In the different samples examined (CS-1 to CS-12) we detected lines of iron, manganese and copper which are linked to the present chromophores, as ascertained by UV-Vis and LIF analysis. Lines of barium, chromium, chlorine, titanium and lead are related to the presence of glass impurities. Emission lines of the main glass components, such as silicon, sodium, calcium, magnesium, aluminum and potassium, were observed for all analyzed samples. We observed that the elemental composition of the historical glasses determined by ns and fs LIBS did not differ significantly, as we detected the same set of elements for each sample in both temporal regimes.

We investigated the influence of laser pulse duration on the plasma characteristics, in particular the number of lines and their relative intensities. As observed in Fig. 4, the line intensity of the major elements in the case of ns pulses (Fig. 4a) is higher than those observed by excitation with fs pulses (Fig. 4b). It is also noticed that, by using the same delay and gate width for signal acquisition, the LIB spectra acquired with ns pulses are richer in line emissions than those corresponding to fs pulses.

Table 4 Elements with their corresponding line emission wavelengths ${ }^{45}$ used for determination of calibration curves with standard and model glass samples

\begin{tabular}{|c|c|c|c|c|c|c|c|c|c|c|c|c|c|}
\hline Element & $\mathrm{Na} \mathrm{I}$ & Mg I & $\mathrm{Al} \mathrm{I}$ & Si I & K I & Ca II & Ti I & Mn I & Fe I & $\mathrm{Cu} \mathrm{I}$ & Ba II & $\mathrm{Pb} \mathrm{I}$ & Cr I \\
\hline Wavelength (nm) & 330.23 & 285.21 & 309.27 & 288.16 & 404.41 & 317.93 & 453.32 & 403.07 & 438.35 & 324.75 & 455.40 & 405.78 & 520.84 \\
\hline
\end{tabular}



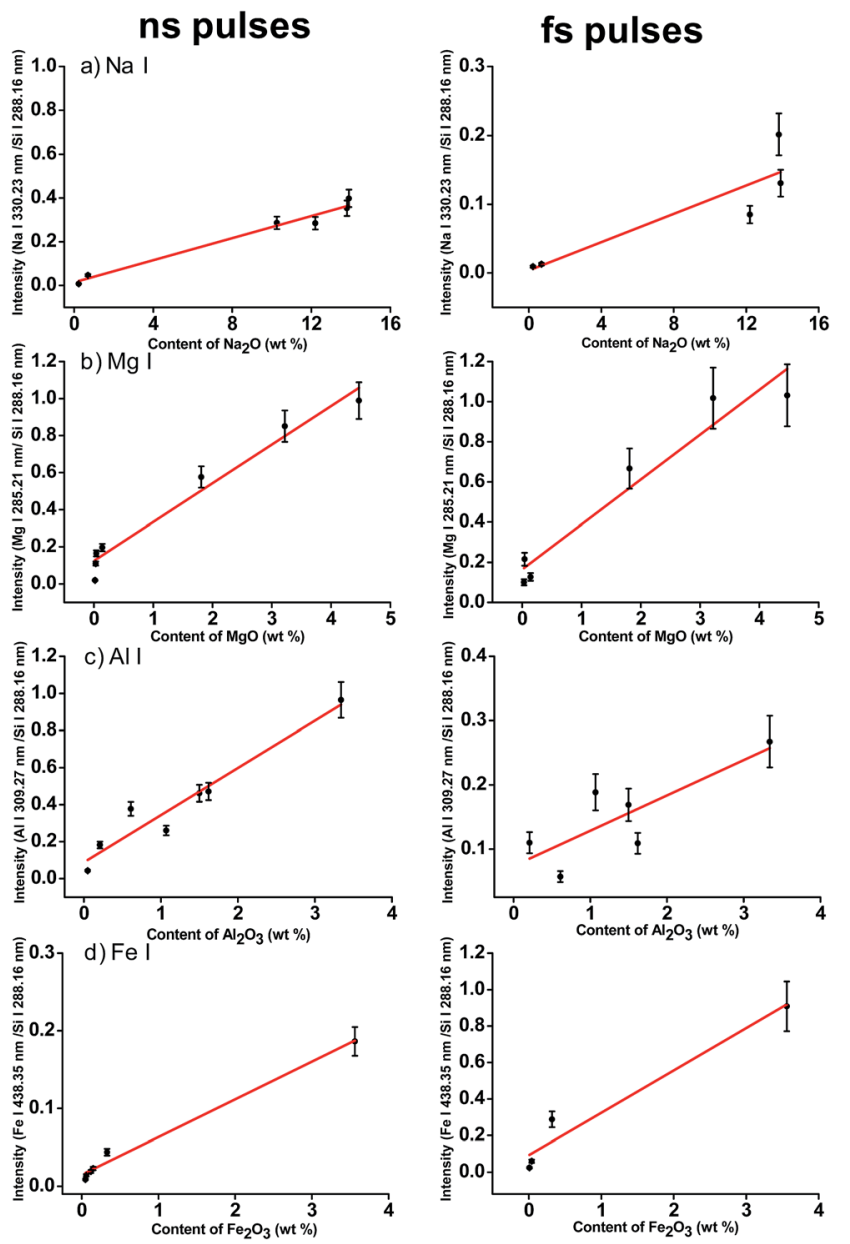

Fig. 5 Calibration curves for: (a) Na I, (b) Mg I, (c) Al I and (d) Fe I for ns (panel on the left) and fs (panel on the right) laser pulses obtained by LIBS analysis of standard and model glass samples.

These differences have their origin in the varying ablation and plasma expansion dynamics taking place with ns and fs pulses. During the interaction of ns laser with the solid, the pulse energy is transferred to the electrons of the lattice, resulting in melting and vaporization of the target. This is followed by the expansion of a vapour plume, which induces a shock wave assisting the ionization of the surrounding gas. Furthermore, the laser pulse interacts with the plasma, leading to efficient reheating by inverse bremsstrahlung absorption. ${ }^{44}$ However, for fs pulses the time scale is shorter than the electron cooling time and the lattice is instantaneously heated, resulting in plasma formation of the vapour and expansion phase.

Table 5 presents a summary of the elemental composition of each historical glass sample as determined by LIBS. The comparison with data derived from XRF (Table 2) reveals that LIBS is able to detect the presence of most of the elements of the compounds identified by XRF, except the elements $\mathrm{P}, \mathrm{S}, \mathrm{Sb}, \mathrm{B}$, As and Zr. This is due to the difficulty to detect these elements in the considered spectral range $(250-600 \mathrm{~nm})$ or to their very low content. However, it was observed that the element chromium was easier to detect by LIBS (especially in the ns mode) than by XRF.

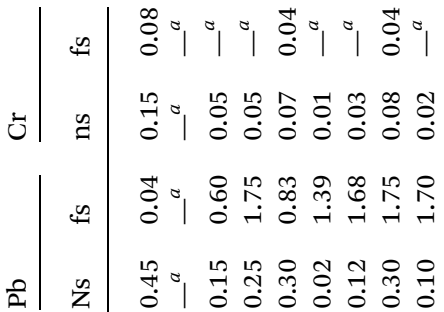

i

œ

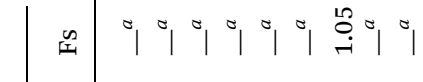

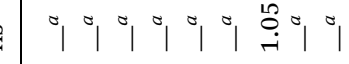

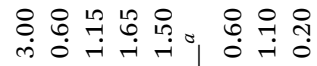

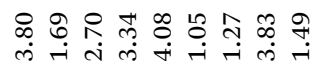

욤 \& 욱 \&

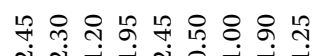

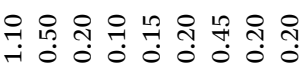

F|

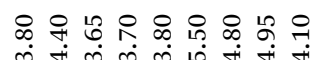

各资

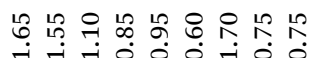

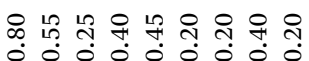

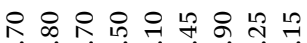
பे में

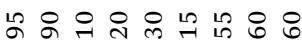

نे

$\ddot{\omega} \cong$

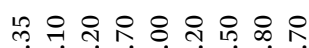

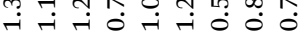

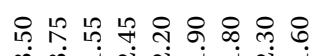

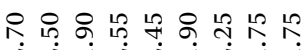
in 4 in 4 4ititi

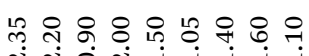

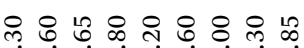
पें ส่ं

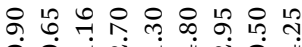

चू च वें

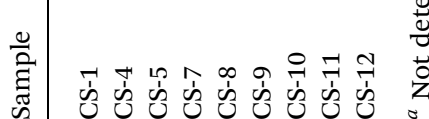


In order to perform quantitative LIBS analysis we obtained calibration curves for the elements appearing in the spectra of the historical glass samples (listed in Table 4). For this purpose we measured LIB spectra, with both ns and fs excitation, of the standard and homemade model glasses listed in Table 3. The line intensities corresponding to a given element in the glass samples were normalized to the Si I emission at $288.16 \mathrm{~nm}$, which was used as an internal standard. This procedure is a common approach in LIBS analysis ${ }^{27}$ and serves to minimize the fluctuations that can arise from matrix effects and laser instability. For quantification of Si itself, the intensity of line at $288.16 \mathrm{~nm}$ was normalized to the intensity of another line of the same element at $390.55 \mathrm{~nm}$. The corresponding relative intensities were represented as a function of the $\mathrm{wt} \%$ content of the compound containing that element as determined by XRF (Table 3). The element Sr, which was detected by LIBS in the Late Roman glasses, could not be quantified due to its absence in the standard and model glasses.

Fig. 5 presents a selection of the calibration curves obtained, for both ns and fs laser irradiation, specifically those for Na I $(330.23 \mathrm{~nm}), \mathrm{Mg} \mathrm{I}(285.21 \mathrm{~nm}), \mathrm{Al} \mathrm{I}(309.27 \mathrm{~nm})$ and Fe I (438.35 $\mathrm{nm})$. The standard deviation, shown with error bars, of the data points for the ns case was significantly lower than that obtained with fs pulses, owing essentially to the more stable energy output of the ns laser and to the effect on line emission intensity of the glass surface roughness for fs pulses. The calibration curves for ns LIBS analysis show a fairly good linearity, with correlation coefficients near unity (0.92-0.98). However, for fs irradiation the calibration curves depart from linearity with correlation coefficients ranging from 0.57 to 0.93 .

Table 5 also shows the results of the quantitative analysis obtained from the described calibration procedure for ns and fs pulses. For the main elements of glasses, silicon and sodium, the elemental composition derived from the ns and fs analyses differs in less than $10 \%$. For the rest of elements detected the differences vary, although in some cases can overcome $100 \%$. As regards the quantitative comparison with XRF results the differences range from 3 to $20 \%$ for main components silicon and sodium and reach considerably higher values for minor components. It is observed that the agreement, in quantitative terms, between LIBS and XRF results, is better achieved in the ns mode owing to the better linearity of calibration curves obtained in this case.

\section{Conclusions}

The technique of laser induced breakdown spectroscopy has been used to analyze the chemical composition of nondestructible historical Late Roman glasses in an integrated analytical approach, which includes, UV-Vis and laser induced fluorescence spectroscopy and X-ray fluorescence (XRF). LIBS allowed the detection of major, minor and trace elements in glasses and the quantitative determination of different compounds for a wide range of concentrations.

Nanosecond and femtosecond laser irradiation yielded almost similar qualitative results, although the LIB spectra acquired in the nanosecond mode contained more line emissions of higher intensities than in the femtosecond mode. Additionally, ns LIBS featured higher sensitivity for minor components such as $\mathrm{Cr}$ and Ba. The differences between LIBS results obtained in the two temporal regimes are attributed to characteristics of plasma expansion dynamics, to varying pulse to pulse fluctuations of ablation pulse energies and to differences in analysis protocols.

For the quantitative data regarding glass chemical composition, nanosecond and femtosecond LIBS results were validated by comparison with those obtained by XRF using a calibration-based method relying on standard and homemade model glasses. Calibration curves for nanosecond LIBS analysis showed better linearity compared to those obtained with femtosecond pulses. For the Late Roman glasses studied this fact led to a more satisfactory agreement, in quantitative terms, between nanosecond LIBS and XRF results.

Consequently it can be concluded that LIBS constitutes a powerful technique to determine glass chromophores and to look for chemical differences or similarities in the body of nondestructible samples with historical value.

The present study demonstrates that LIBS is a useful, promising and alternative technique for investigation of historical glasses, especially for those conserved under burial conditions and, generally speaking, for the study of nondestructible materials of cultural heritage. The speed of analysis achieved with this technique facilitates the examination of a large number of samples in the field, at an excavation site, or in a museum. Also, the development and production of portable LIBS devices alone or in combination with other analytical techniques, which would enable analysis on site, are the subject of intense research, as technological advances offer more and more options for compact laser sources and detection equipment.

\section{Acknowledgements}

This work was funded by MINECO (Project CTQ2013-43086-P, HAR2012-30769 and FIS2013- 44174-P) and Programa Geomateriales 2-CM (CAM, S2013/MIT-2914) and counted with the support from Techno-Heritage (Spanish Network of Science and Technology for Heritage Conservation). M. Oujja acknowledges CSIC for a contract.

\section{References}

1 R. Noll, Laser-induced Breakdown Spectroscopy, Springer, 2012.

2 E. Tognoni, V. Palleschi, M. Corsi and G. Cristoforetti, Quantitative micro-analysis by laser-induced breakdown spectroscopy: a review of the experimental approaches, Spectrochim. Acta, Part B, 2002, 57, 1115-1130.

$3 \mathrm{~J}$. M. Vadillo and J. J. Laserna, Laser-induced plasma spectrometry: truly a surface analytical tool, Spectrochim. Acta, Part B, 2004, 59, 147-161.

4 D. W. Hahn and N. Omenetto, Laser induced breakdown spectroscopy (LIBS), part II: review of instrumental and methodological approaches to material analysis and 
applications to different fields, Appl. Spectrosc., 2012, 66, 347-419.

5 V. Lazic, F. Colao, R. Fantoni and V. Spizzicchino, Laserinduced breakdown spectroscopy in water: improvement of the detection threshold by signal processing, Spectrochim. Acta, Part B, 2005, 60, 1002-1013.

6 M. Hidalgo Nuñez, P. Cavalli, G. Petrucci and N. Omenetto, Analysis of sulfuric acid aerosols by laser-induced breakdown spectroscopy and laser-induced photofragmentation, Appl. Spectrosc., 2000, 54, 1805-1816.

7 Q. Sun, M. Tran, B. W. Smith and J. D. Winefordner, Determination of $\mathrm{Mn}$ and $\mathrm{Si}$ in iron ore by laser-induced plasma spectroscopy, Anal. Chim. Acta, 2000, 413, 187-195.

8 I. Osticioli, J. Agresti, C. Fornacelli, I. T. Memmi and S. Siano, Potential role of LIPS elemental depth profiling in authentication studies of unglazed earthenware artifacts, J. Anal. At. Spectrom., 2012, 27, 827-833.

9 K. Melessanaki, M. Mateo, S. C. Ferrence, P. P. Betancourt and D. Anglos, The application of LIBS for the analysis of archaeological ceramic and metal artifacts, Appl. Surf. Sci., 2002, 197-198, 156-163.

10 A. Giakoumaki, K. Melessanaki and D. Anglos, Laserinduced breakdown spectroscopy (LIBS) in archaeological science-applications and prospects, Anal. Bioanal. Chem., 2007, 387, 749-760.

11 A. A. Bol'shakov, J. H. Yoo, C. Liu, J. R. Plumer and R. E. Russo, Laser-induced breakdown spectroscopy in industrial and security applications, Appl. Opt., 2010, 49, C132-C142.

12 B. Castle, K. Talabardon, B. W. Smith and J. D. Winefordner, Variables influencing the precision of laser-induced breakdown spectroscopy measurements, Appl. Spectrosc., 1998, 52, 649-657.

13 D. W. Hahn and N. Omenetto, Laser-induced breakdown spectroscopy (LIBS), part I: review of basic diagnostics and plasma-particle interactions: still-challenging issues within the analytical plasma community, Appl. Spectrosc., 2010, 64, 335-366.

14 K. L. Eland, D. N. Stratis, D. M. Gold, S. R. Goode and S. Michael Angel, Energy dependence of emission intensity and temperature in a LIBS plasma using femtosecond excitation, Appl. Spectrosc., 2001, 55, 286-291.

15 A. Semerok, C. Chaléard, V. Detalle, J. L. Lacour, P. Mauchien, P. Meynadier, C. Nouvellon, B. Sallé, P. Palianov, M. Perdrix and G. Petite, Experimental investigations of laser ablation efficiency of pure metals with femto, pico and nanosecond pulses, Appl. Surf. Sci., 1999, 138-139, 311-314.

16 P. Stavropoulos, C. Palagas, G. N. Angelopoulos, D. N. Papamantellos and S. Couris, calibration measurements in laser-induced breakdown spectroscopy using nanosecond and picosecond lasers, Spectrochim. Acta, Part B, 2004, 59, 1885-1892.

17 A. De Giacomo, M. Dell'Aglio, A. Santagata and R. Teghil, Early stage emission spectroscopy study of metallic titanium plasma induced in air by femtosecond- and nanosecond-laser pulses, Spectrochim. Acta, Part B, 2005, 60, 935-947.

18 R. E. Russo, X. L. Mao, C. Liu and J. Gonzalez, Laser assisted plasma spectrochemistry: laser ablation, J. Anal.At. Spectrom., 2004, 19, 1084-1089.

19 J. Koch, A. A. Von Bohlen, R. Hergenröder and K. Niemax, Particle size distributions and compositions of aerosols produced by near-IR femto- and nanosecond laser ablation of brass, J. Anal. At. Spectrom., 2004, 19, 267-272.

20 V. Margetic, M. Bolshov, A. Stockhaus, K. Niemax and R. Hergenröder, Depth profiling of multi-layer samples using femtosecond laser ablation, J. Anal. At. Spectrom., 2001, 16, 616-621.

21 M. Corsi, G. Cristoforetti, M. Giuffrida, M. Hidalgo, S. Legnaioli, L. Masotti, V. Palleschi, A. Salvetti, E. Tognoni, C. Vallebona and A. Zanini, Archaeometric Analysis of Ancient Copper Artefacts by Laser-Induced Breakdown Spectroscopy Technique, Microchim. Acta, 2005, 152(1-2), 105-111.

22 A. Elhassan, A. Giakoumaki, D. Anglos, G. M. Ingo, L. Robbiola and M. A. Harith, Nanosecond and femtosecond Laser Induced Breakdown Spectroscopic analysis of bronze alloys, Spectrochim. Acta, Part B, 2008, 63(4), 504-511.

23 V. Lazic, R. Fantoni, F. Colao, A. Santagata, A. Morone and V. Spizzichino, Quantitative laser induced breakdown spectroscopy analysis of ancient marbles and corrections for the variability of plasma parameters and of ablation rate, J. Anal. At. Spectrom., 2004, 19(4), 429-436.

24 A. Erdem, A. Çilingiroğlu, A. Giakoumaki, M. Castanys, E. Kartsonaki, C. Fotakis and D. Anglos, Characterization of Iron age pottery from eastern Turkey by laser- induced breakdown spectroscopy (LIBS), J. Archaeol. Sci., 2008, 35(9), 2486-2494.

25 P. Westlake, P. Siozos, A. Philippidis, C. Apostolaki, B. Derham, A. Terlixi, V. Perdikatsis, R. Jones and D. Anglos, Studying pigments on painted plaster in Minoan, Roman and Early Byzantine Crete. A multianalytical technique approach, Anal. Bioanal. Chem., 2012, 402(4), 1413-1432.

26 O. Kokkinaki, C. Mihesan, M. Velegrakis and D. Anglos, Comparative study of laser induced breakdown spectroscopy and mass spectrometry for the analysis of cultural heritage materials, J. Mol. Struct., 2013, 1044, 160166.

27 K. Müller and H. Stege, Evaluation of the analytical potential of laser-induced breakdown spectrometry (LIBS) for the analysis of historical glasses, Archaeometry, 2003, 45(3), 421-433.

28 N. Carmona, M. Oujja, S. Gaspard, M. García-Heras, M. A. Villegas and M. Castillejo, Lead determination in glasses by laser-induced breakdown spectroscopy, Spectrochim. Acta, Part B, 2007, 62(2), 94-100.

29 N. Carmona, M. Oujja, E. Rebollar, H. Römich and M. Castillejo, Analysis of corroded glasses by laser induced breakdown spectroscopy, Spectrochim. Acta, Part B, 2005, 60(7-8), 1155-1162. 
30 T. Palomar, M. Oujja, M. García-Heras, M. A. Villegas and M. Castillejo, Laser induced breakdown spectroscopy for analysis and characterization of degradation pathologies of Roman glasses, Spectrochim. Acta, Part B, 2013, 87, 114-120.

31 S. Klein, T. Stratoudaki, V. Zafiropulos, J. Hildenhagen and K. Dickmann, Th. Lehmkuhl, Laser-induced breakdown spectroscopy for on-line control of laser cleaning of sandstone and stained glass, Appl. Phys. A, 1999, 69, 441.

32 C. Gerhard, J. Hermann, L. Mercadier, L. Loewenthal, E. Axente, C. R. Luculescu, T. Sarnetb, M. Sentis and W. Viöl, Quantitative analyses of glass via laser-induced breakdown spectroscopy in argon, Spectrochim. Acta, Part $B, 2014,101,32-45$.

33 E. Negre, V. Motto-Ros, F. Pelascini, S. Lauper, D. Denis and J. Yu, On the performance of laser-induced breakdown spectroscopy for quantitative analysis of minor and trace elements in glass, J. Anal. At. Spectrom., 2015, 30, 417-425.

34 J. D. Pedarnig, P. Kolmhofer, N. Huber, B. Praher, J. Heitz and R. Rössler, Element analysis of complex materials by calibration-free laser-induced breakdown spectroscopy, Appl. Phys. A, 2013, 112, 105-111.

35 C. Isings, Roman Glass from Dated Finds, ed. J. W. Wolter, Groningen, 1957.

36 R. W. Douglas and S. Frank, A History of Glassmaking, G. T. Foulis and Co. Ltd., London, 1972.

37 T. Palomar, M. García-Heras, R. Sabio, J. Ma. Rincón and M. A. Villegas, Composition, preservation and production technology of Augusta Emerita Roman glasses from the first to the sixth century AD, Mediterr. Archaeol. Archaeom., 2012, 12, 193-211.
38 D. Allen, Roman Glass in Britain, Shire Publications, Princes Risborough, Buckinghamshire, 1998.

39 C. M. Jackson, H. E. M. Cool and E. C. W. Wager, The manufacture of glass in Roman York, J. Glass Stud., 1998, 40, 55-61.

40 H. D. Smith, C. P. McKay, A. G. Duncan, R. C. Sims, A. J. Anderson and P. R. Grossl, An instrument design for non-contact detection of biomolecules and minerals on Mars using fluorescence, J. Biol. Eng., 2014, 8(16), 1-14.

41 S. C. Hill, M. W. Mayo and R. K. Chang, Fluorescence of Bacteria, Pollens, and Naturally Occurring Airborne Particles: Excitation/Emission Spectra, Army Research Laboratory, Adelphi, MD 20783-1197, 2009, http:/www.dtic.mil/cgibin/GetTRDoc?AD=ADA494347.

42 E. V. Pestryakov, V. V. Petrov, V. I. Trunov, A. V. Kirpichnikov, A. G. Volkov, A. I. Alimpiev and A. J. Rodionov, $\mathrm{Be}_{3} \mathrm{Al}_{2} \mathrm{Si}_{6} \mathrm{O}_{18}$ Crystals Doped with Jahn-Teller Ions:A Promising Active Media for Super broad band Lasers, Laser Phys., 2001, 11, 1138-1141.

43 R. W. B. Pearse and A. G. Gaydon, The Identification of Molecular Spectra, Chapman and Hall Ltd, London, 3rd edn, 1963.

44 K. L. Eland, D. N. Stratis, T. Lai, M. A. Berg, S. R. Goode and S. M. Angel, Some comparisons of LIBS measurements using nanosecond and picosecond laser pulses, Appl. Spectrosc., 2001, 55, 279-285.

45 NIST electronic database, at http://physics.nist.gov/ PhysRefData. 